\title{
Conflictos por tomas de tierras y modos de intervención estatal: análisis de una experiencia del Alto Valle de Río Negro (Argentina)
}

\author{
Mariana Andrea Giaretto ${ }^{1}$ y \\ Victoria Yasmín Naffa ${ }^{2}$
}

Fecha de recepción: 18 de agosto de 2015

Fecha de aprobación: 23 de marzo de 2016

\begin{abstract}
Resumen
En este trabajo analizamos las relaciones entre tomas de tierras y Estado, en el Alto Valle de Río Negro en Argentina. En un contexto general de especulación inmobiliaria, por la que se encarecen los precios de alquileres y terrenos, y de políticas de vivienda selectivas y acotadas, los sectores populares acceden a un espacio en la ciudad mediante tomas de tierras. Frente a estos conflictos, el Estado, en sus diferentes niveles y poderes, despliega una forma de intervención basada en la criminalización de las luchas por tierra y vivienda. Al mismo tiempo, el poder ejecutivo nacional crea la Secretaría de Acceso al Hábitat, para posibilitar la intervención política orientada a la regularización de los asentamientos. Sin embargo, esta intervención tiende a reinscribir la problemática habitacional en el campo político, para reducirla a un conflicto "entre partes", eludiendo la responsabilidad estatal.

Desde un enfoque metodológico cualitativo, seleccionamos como referente empírico el caso del asentamiento de Villa Obrera en Fiske, Menuco (Gral. Roca), y las técnicas de recolección de datos se basan en fuentes secundarias, como expedientes judiciales y normativa, y en fuentes primarias como son los relatos de los protagonistas mediante entrevistas individuales y colectivas ${ }^{3}$.
\end{abstract}

Palabras clave: tomas de tierras, Estado, criminalización de los conflictos.

\footnotetext{
1 Magíster en Teoría y Metodología de las Ciencias Sociales (CLACSO/FLACSO), Licenciada en Sociología (Universidad Nacional de La Plata, Argentina), Profesora Adjunta Regular e investigadora de la Universidad Nacional del Comahue, Cipolletti, Argentina, e-mail: marianatt3010@yahoo.com.ar

2 Maestranda en Criminología y Abogada de la Universidad Nacional del Comahue. Docente de la Universidad Nacional de Río Negro e investigadora de la Universidad Nacional del Comahue, General Roca, e-mail: vic_naffa@hotmail.com 3 Este trabajo se inscribe en el proyecto de investigación "Luchas territoriales y forma de Estado en la posconvertibilidad" (Código 04/D104) y del proyecto de extensión "Mapeo colectivo de luchas territoriales", ambos de la Universidad Nacional del Comahue, Argentina.
} 


\title{
Conflicts caused by land occupation and modes of State intervention: analysis of an experience of Alto Valle in Río Negro (Argentina)
}

\begin{abstract}
This paper analyzes the relationship between State and land occupation, at Alto Valle in Río Negro, Argentina. In a general context of real estate speculation, where rents and land prices are expensive, and a policy of selective and limited housing, popular sectors can have access to a space in the city through land occupation. In front of these conflicts, the State in its different levels and powers, displays a form of intervention based on the criminalization of struggles for land and housing. At the same time, the national executive creates the Secretariat of Access to Habitat, oriented to allow political intervention for the regularization of settlements. However, this intervention tends to re-register the housing problems in the political arena, reducing it to a conflict "between parties" and eluding the responsibility of the State.

From a qualitative methodological approach, we selected as empirical reference the case of the settlement of Villa Obrera in Fiske, Menuco (General Roca). The techniques of data collection are based on secondary sources, such as policy and legal records, and primary sources as the stories of protagonists through individual and collective interviews
\end{abstract}

Keywords: land occupation, State, criminalization of conflicts.

\section{Conflitos sobre ocupações de terras e modos de intervenção do estado: análise de uma experiência do Alto Valle do Rio Preto (Argentina)}

\section{Resumo}

Este trabalho analisa as relações entre a posse de terra e o Estado, no Alto Valle do Rio Preto, na Argentina. Num contexto geral da especulação imobiliária, por qual se encarecem os preços do aluguel e das terras, e de políticas de habitação seletivas e limitadas, os setores populares acedem a um espaço na cidade através de ocupações de terras. Frente a estes conflitos, o Estado, em seus diferentes níveis e poderes, desenvolve uma forma de intervenção com base na criminalização das lutas pela terra e vivenda. Ao mesmo tempo, o poder executivo nacional cria a Secretaria de Acesso à Habitat para possibilitar à intervenção política orientada a regularização dos assentamentos. No entanto, esta intervenção tende a registrar os problemas de habitação no campo político, para reduzi-la a um conflito "entre as partes", iludindo a responsabilidade do Estado.

A partir de uma abordagem metodológica qualitativa, foi selecionado como referência empírica o caso do Assentamento de Villa Obrera em Fiske, Menuco (Gral. Roca), e as técnicas de recolecção de dados são baseados em fontes secundárias, como expedientes judiciais e normativos, e em fontes 
primárias como são as histórias dos protagonistas através de entrevistas individuais e coletivas ${ }^{4}$.

Palavras-chave: tomada de terras, Estado, criminalização dos conflitos.

\section{Introducción}

En estos primeros quince años del siglo XXI, el déficit habitacional es un problema que atraviesa la cotidianidad y subsistencia de miles de familias argentinas. Según el último Censo de 2010, son aproximadamente 3.000 .000 de hogares afectados por la problemática de la precariedad habitacional. Para comprender la gravedad de esta situación, nos proponemos realizar un análisis crítico de los modos en los que interviene el Estado en las experiencias concretas de tomas de tierras en el Alto Valle de Río Negro. Nuestra hipótesis central es que el Estado despliega una doble estrategia: al mismo tiempo que criminaliza los conflictos por tierra y vivienda, activa ciertos mecanismos de capitalización política de estos conflictos. En este sentido, nuestras preguntasguías en la investigación son: ¿en qué consiste la criminalización de los conflictos por tomas de tierras? ¿Cómo y por qué el Estado interviene judicializando estos conflictos? ¿Cómo se da la intervención de la Secretaría de Acceso al Hábitat en las experiencias concretas? ¿Cómo se caracteriza la situación actual de estos conflictos?

Para avanzar en nuestro análisis, es necesario definir algunos conceptos clave. Nuestro marco teórico parte de una noción de Estado que, lejos de entenderlo como un simple instrumento de las clases dominantes, lo considera como el lugar donde se unifica y organiza la dominación y donde se divide y desorganiza a los sectores subalternos (Poulantzas, 1983). Esto quiere decir que el Estado es arena de la lucha de clases, es espacio, es

4 Este trabalho se inscreve no projeto de investigação "Lutas territoriais e forma do Estado na posconvertibilidade" (Código 04/D104) e do projeto de extensão "Mapeio coletivo de lutas territoriais, os dois da Universidade Nacional de Comahue, Argentina". 
proceso y también prácticas en disputa. De allí que en el Estado se desenvuelva un inestable equilibrio de compromisos entre la clase dirigente y los sectores subalternos (Gramsci, 2004), cristalizándose institucionalmente en contradicciones internas. En tanto condensación material de una relación de fuerzas determinada (Poulantzas, 1983), el Estado está compuesto por diversos aparatos que desempeñan funciones específicas en diversos niveles. En este trabajo distinguiremos cuando estemos refiriéndonos al poder ejecutivo, legislativo y/o judicial, así como al nivel local, provincial y nacional, pero asumiendo que las contradicciones entre ellos no quitan cierta organicidad del Estado capitalista.

Entendemos por tomas de tierras a formas de organización colectiva que posibilitan el acceso al derecho a la vivienda de los sectores populares, por lo que deviene en un mecanismo de autourbanización precaria, común a gran parte de las ciudades de América Latina (Giaretto, 2011).

Abordamos a la criminalización como un complejo proceso por el que se convierten los conflictos sociales en delitos. Esto implica la aplicación selectiva del derecho penal y civil para disciplinar a quienes los protagonizan. El proceso de criminalización consiste en:

(...) el avance del proceso de judicialización de los conflictos, visible en la multiplicación y el agravamiento de las figuras penales, en la manera que éstas son aplicadas por jueces y fiscales, en el número de procesamientos a militantes populares, en la estigmatización de las poblaciones y grupos movilizados, en el incremento de las fuerzas represivas y en la creación especial de cuerpos de elite, orientados a la represión y militarización de las zonas de conflicto. Por todos estos caminos, los problemas sociales y políticos se vuelven procesos penales. (Korol, 2009, p. 84). 
Cuando problematizamos la capitalización política de los conflictos, estamos haciendo referencia a discursos y prácticas que se cristalizan en operaciones desenvueltas por el Estado para obtener beneficios políticos de los procesos de resolución de dichos conflictos. Para abordar metodológicamente estos conceptos y lograr producir conocimiento contextualizado de la problemática planteada, desplegamos técnicas de recolección de fuentes secundarias, accediendo a los expedientes de las causas judiciales y documentación oficial y también periodística sobre el funcionamiento de la Secretaría de Acceso al Hábitat, así como técnicas de recolección de fuentes primarias sobre la base de entrevistas/encuentros individuales y colectivos con los referentes y vecinos de los asentamientos. Desde una estrategia metodológica que recupera los supuestos de la Investigación Acción Participación (Fals, 2012), lejos de la extracción instrumental de información, se trata de construir conocimiento contextualizado a partir del diálogo de saberes técnicos y aprendizajes populares. En primer lugar, realizamos dos entrevistas exploratorias con los referentes de la toma, luego comenzamos a trabajar en el acompañamiento y asesoramiento jurídico-técnico para realizar la defensa en el marco del juicio oral. Este proceso implicó encuentros semanales durante dos meses, desde septiembre a noviembre. En una ocasión fue un encuentro de tipo asambleario con gran parte de los vecinos del barrio y en el resto de las ocasiones fueron con los referentes judicializados.

A partir de una articulación de perspectivas macro y microsociales en la explicación de las tomas de tierras, se realizó un análisis temático de la información desde dos núcleos centrales: el proceso de organización y consolidación de la toma de tierra y el proceso de criminalización por parte del Estado. Desde una reconstrucción narrativa-histórica (Sautu, Boniolo, Dalle y Elbert, 2005), se identificaron momentos significativos de estos procesos y se analizaron desde las interpretaciones de los propios protagonistas y desde las perspectivas teóricas seleccionadas, generando en la intersección de ambas interpretaciones un conocimiento contextualizado y crítico. 


\section{La profundización del problema de la vivienda durante el kirchnerismo}

Para aproximarnos a este problema, es necesario explicitar desde qué nociones básicas interpretamos los procesos implicados durante las gestiones kirchneristas, y, en este sentido, será imprescindible discutir las versiones y explicaciones oficiales. $\mathrm{Si}$ bien los datos y estadísticas oficiales que sustentan los discursos del kirchnerismo son al menos cuestionables, desde la intervención del Instituto Nacional de Estadísticas y Censos INDEC, consideramos que la gravedad y urgencia de la precarización habitacional es innegable, aun si consideramos fidedignos los datos que sostienen esos discursos. Es la propia Secretaría Nacional de Acceso al Hábitat la que sostiene que: "La situación habitacional en la Argentina requiere de atención, debido a que se ha acumulado durante muchos años un déficit habitacional que hoy asciende estimativamente a dos millones y medio de hogares" ${ }^{\prime \prime}$. Y argumenta que:

La informalidad y el déficit habitacional que sufre una parte importante de la población es producto de la mecánica de acumulación y concentración de la riqueza que se desarrolló durante la década de los '90. Esta política destruyó la estructura productiva, provocó desocupación, pobreza, indigencia, hambre y disgregación social. (Ídem)

Bajo esta visión, hay una serie de supuestos que es necesario problematizar: uno de tipo ético-político, por el que la gravedad de una situación social se mide en miles, si es posible millones; es decir, que una, dos o trescientas familias transcurran su vida cotidiana en la precariedad habitacional no es un problema que requiera atención del Estado, pero si son millones de familias en-

\footnotetext{
5 Ver sitio oficial de la Comisión Nacional de Tierras, consultado en http:/ / www. tierras.gob.ar/index.php
} 
tonces sí. Este criterio cuantitativo para definir como grave o no grave la situación de riesgo de vida de las personas es, al menos desde un comienzo, cuestionable, aunque reconocemos que esté absolutamente naturalizado en el sentido común y la opinión pública en general. Más allá de este cuestionamiento, es necesario dimensionar la gravedad de esta problemática, a pesar de que los registros oficiales sean poco confiables. Otro supuesto de tipo teórico-político es que las causas de esta situación no sólo se remontan a la mecánica de acumulación propia de los años noventa, sino que además esa mecánica de acumulación habría finalizado, habría sido combatida y superada por las políticas del proyecto kirchnerista. Discutamos estos supuestos, al mismo tiempo que caracterizamos y definimos una interpretación crítica de esta situación.

Analicemos en primer término lo que, luego de doce años en el gobierno, el poder ejecutivo nacional admite como una situación que requiere atención y que afecta a más de dos millones y medio de hogares. Según los datos del último Censo Nacional de Población y Viviendas de 2010, más de 3.000 .000 de hogares se encuentran afectados por algún tipo de problema de vivienda, esto quiere decir que 10.000.000 de personas sufren la precariedad habitacional. Entre los principales problemas habitacionales encontramos que 2.145.224 hogares se ven afectados por alojarse en vivienda inadecuadas, 179.796 sufren hacinamiento en el hogar (más de tres personas por cuarto) y 1.061 .886 sufren hacinamiento de hogares (más de un hogar por vivienda), lo que hace un total de 3.386 .606 hogares con problemas de vivienda (Putero, 2010).

Basta con ponerle rostro a estas estadísticas para dimensionar la gravedad de la situación habitacional en la que transcurren sus vidas niños, ancianos, mujeres y hombres que, además de soportar la precariedad de su espacio vital, sin acceso a agua potable, a drenaje, sin acceso a gas $u$ otras formas seguras para calefaccionarse, sin conexiones seguras de electricidad, deben enfrentar la exposición a la incertidumbre permanente que en una sociedad 
capitalista genera la falta de un título de propiedad, soportando diversas formas de criminalización ${ }^{6}$.

Pero antes de analizar la criminalización de los conflictos por tierra y vivienda como política estatal ${ }^{7}$, veamos cómo entendemos a este Estado y cuáles son sus particularidades, discutiendo y desautorizando la versión oficial que desplaza las causas del problema a las políticas neoliberales de los noventa.

Entonces, según la Secretaría Nacional de Acceso al Hábitat y, por lo tanto, para el poder ejecutivo nacional, la mecánica de acumulación neoliberal destruyó la estructura productiva, provocó desocupación, pobreza, indigencia, hambre y disgregación social. Si bien aquí no podemos profundizar en los rasgos de lo que denominan "mecánica de acumulación neoliberal", sí consideramos sumamente necesario desmitificar algunos supuestos sobre los que descansa este tipo de discurso.

Para construir e imponer como interpretación válida del modelo actual de acumulación y dominación, el kirchnerismo ha distorsionado ciertos procesos históricos, lo que le permite hacer del neoliberalismo un enemigo al que supuestamente se opone. En este sentido, la tesis de financiarización de la economía simplifica la complejidad de operaciones internas a la lógica del capital, para asumir como real la escisión entre capital financiero y capital productivo, como también el supuesto juego de suma cero entre Estado y mercado, de tal manera que, en los años noventa, el capital productivo habría sido víctima de la supremacía del capital finan-

\footnotetext{
6 Ver Giaretto y Naffa, 2014: “Cuando habitar la tierra es 'delito'. La criminalización de las luchas por la tierra en ciudades del Alto Valle de Río Negro", ponencia presentada en las VI Jornadas de Historia de la Patagonia, Facultad de Ciencias de la Educación, Universidad Nacional del Comahue, Cipolletti, 12, 13 y 14 de noviembre.

7 En este sentido, es significativo remarcar que, según el Informe sobre Criminalización de la Protesta, entre 2001 y 2012 el tipo de conflicto con mayor porcentaje de criminalización ha sido aquel que involucra los derechos y reclamos por tierra y vivienda, con un 32,3\% del total de los casos. Pero además, Río Negro es la segunda provincia del país con uno de los índices más altos de criminalización: 23,4\%, tras Ciudad y Provincia de Buenos Aires con el $48 \%$.
} 
ciero, debido a una supuesta malicia del Estado en la regulación del mercado que favoreció dicha financiarización de la economía.

Lo cierto es que, si bien ciertas ramas de la producción se vieron seriamente afectadas por las políticas de apertura comercial selectiva y de desregulación financiera total, diagnosticar una destrucción de la estructura productiva no coincide con la realidad. La comparación de ciertos datos macroeconómicos impide hacer un corte abrupto entre las políticas neoliberales de los noventa y las actuales. Según datos del INDEC, la participación de la intermediación financiera en el PBI en 1996 era de 6,1\%, mientras que en 2008 era del 5,3\%, una variación que al menos indicaría ciertas reservas al momento de hablar de un modelo de acumulación que arremete contra el capital financiero. Pero veamos además que detrás del discurso de reindustrialización también surgen ciertas inconsistencias, ya que la participación de las industrias manufactureras en el PBI en 1996 era de 17,4\%, y en 2008 de 16,1\% (Astarita, 2010). A esto podemos agregar que, si el capital productivo realmente hubiese sido víctima de la valorización financiera, ¿cómo se explica que la tasa de explotación durante los noventa haya aumentado al menos el 58,2\%? (Salvia, 2009). El punto justamente es despejar que el antagonismo central en una sociedad capitalista es entre capital y trabajo, no entre capital financiero y capital productivo, y por lo tanto los conflictos no se reducen a las pujas interburguesas, sino que implican la complejidad de la lucha de clases.

De allí que, lejos de establecer una simple continuidad entre las políticas neoliberales y las del kirchnerismo, lo que intentamos demostrar es que, más que establecer continuidades y rupturas, se trata de reconocer bajo qué formas particulares transmuta el capitalismo dependiente en la Argentina, y por qué el problema de la vivienda es una manifestación constante, a pesar de esta transmutación.

No hay duda de que las políticas posconvertibilidad -incluimos la gestión de Duhalde y las kirchneristas- lograron re- 
vertir la recesión de fines de los noventa y de que lo hicieron adjudicándole el costo de la crisis de acumulación de 2001 a determinados sectores, particularmente las familias trabajadoras. Si durante los años noventa la modalidad de disciplinamiento para controlar el costo salarial combinaba convertibilidad/ desocupación, en la posconvertibilidad la modalidad combinó inflación/precarización laboral (Grigera y Esquenazi, 2013). Lo que explica cómo funciona el modelo de acumulación actual a través del chantaje inflacionario y la precarización laboral como variable de ajuste.

Entonces, si los sectores populares son "incluidos" mediante la precarización laboral, resulta lógico que hablemos de precarización habitacional en lo que respecta al acceso a la vivienda. Al parecer:

(...) la continuidad de ciertos rasgos a lo largo de dos décadas es antes el producto de la profundización de la reestructuración neoliberal y reproducción en los años siguientes, que la simple persistencia (...) el agotamiento del ciclo neoliberal es también el producto de su éxito y lo que sigue a las llamadas reformas estructurales debe explicarse como fenómeno novedoso. (Grigera y Esquenazi, 2013, p. 166).

Si consideramos que el problema de la vivienda es una cuestión en la que se ven implicados los diferentes poderes de Estado y sus distintos niveles jurisdiccionales, entonces cabe preguntarnos cuál es la especificidad de las relaciones entre poderes y sus niveles bajo el Estado kirchnerista.

La noción de forma de Estado permite acercarnos a las características que reviste el Estado capitalista en cierto periodo histórico, en un territorio nacional particular, y, en este sentido, posibilita caracterizar un conjunto de instituciones que constituyen los aparatos estatales y un conjunto de actividades que comprenden las funciones del Estado (Bonnet y Piva, 2013). Entonces, analicemos los rasgos particulares que asumen aquellos aparatos 
y aquellas funciones del aparato estatal que intervienen en los conflictos por tomas de tierras.

La problemática habitacional es, sin lugar a dudas, una manifestación de una forma particular de relación entre Estado y mercado, en la medida en que el acceso a la vivienda es absolutamente mediado por la acumulación concentrada y especulativa de la clase propietaria, y el Estado, lejos de regular la lógica de mercado, interviene promoviendo la financiarización y el acceso por endeudamiento de los sectores no propietarios (Giaretto y Tetamanti, 2013). Sin embargo, para las familias de trabajadores precarizados, a la ciudad se accede por la ocupación de tierras y la autourbanización.

Asimismo, las relaciones interiorizadas entre lo político y lo económico en el propio Estado, entre los diferentes poderes y niveles, aparecen claramente en los modos de intervención en los conflictos de tierras -en los que se ven implicados los poderes ejecutivo, legislativo y judicial, y los niveles municipal, provincial y nacional-, en la criminalización de los conflictos y en la capitalización política por parte de la Secretaría de Acceso al Hábitat.

\section{Conflictos por tomas de tierras y criminalización como política de Estado}

La configuración de la situación delictual y los procesos de criminalización de las luchas por tierra y vivienda son impensables sin el accionar del Estado en su conjunto, en la medida en que es parte de los condicionamientos concretos de dichos procesos. Lo cierto es que en las sociedades capitalistas, el Estado despliega una serie de mecanismos de mediación en los conflictos entre las clases antagónicas.

En términos de Therborn, la centralización y la totalización son mecanismos para la mediación del Estado en la lucha de clases. Mientras la primera implica centralizar los recursos de la clase dominante en el gran aparato del Estado, la segunda consiste en la in- 
clusión de todas las clases en el Estado. Con esta tensión de fondo, el Estado intenta mostrarse como árbitro neutro de los conflictos entre las clases sociales, pero lo cierto es que su carácter de clase se manifiesta en diversos procesos de mediación que intentan desde la sumisión a la colaboración de las clases dominadas. Uno de esos procesos es la judicatura, por la que “(...) el aparato judicial del Estado media en las relaciones entre dominadores y dominados, proporcionando instituciones de apelación a las cuales pueden presentarse para su resolución los conflictos entre los individuos o grupos de las diferentes clases" (Therborn, 1979, p. 289).

En este sentido, la judicatura resulta un proceso de mediación que posibilita la inclusión de los diferentes grupos sociales en el Estado (totalización); sin embargo, es una inclusión selectiva, direccionada, que tiende a garantizar como efecto primario de dicho proceso la sumisión más que la colaboración de las clases dominadas.

Cabe remarcar que el mecanismo de judicatura en relación con los procesos de lucha por tierra y vivienda, implica tanto la judicialización civil, circunscripta a una disputa entre "privados", como la judicialización en sentido penal, en la cual el Estado despliega su poder punitivo en contra de quien considera infractor de la ley penal. Ambas formas son, a su vez, parte del proceso de criminalización, que convertirá a la lucha por la tierra en un "delito", y a quienes luchen por ella en "delincuentes".

En términos concretos, la criminalización implica el despliegue del aparato punitivo como forma de intervención en los conflictos por tierra y vivienda. Es necesario dejar de lado la representación normativa del sistema de justicia, que parte de la base de que la misma es ejercida por un órgano independiente del poder político, y su actividad se limita a la aplicación estricta de la ley. Porque no nos interesa detenernos en las funciones explícitas y manifiestas del Poder Judicial (investigación y juzgamiento de delitos), sino en aquellas que permanecen en lo oculto, es decir, lo que se denomina "funciones latentes". 
¿Cuál es la finalidad de la utilización del sistema penal en este tipo de conflictos? La figura penal utilizada para la criminalización de conflictos de tierra y vivienda es principalmente el tipo penal de usurpación (181 CP), que prevé como sanción la pena de prisión. Sin embargo, no parece ser esta la finalidad del proceso penal en estos conflictos.

La judicialización puede ser entendida como una forma de criminalización, si la consideramos parte de una convergencia de prácticas judiciales, penales (sanción o modificación de leyes) y policiales aplicadas ante los conflictos de tierras y vivienda, que tienden a una verdadera criminalización del conflicto, es decir, la aplicación del aparato punitivo/penal. Entonces la judicialización en sentido amplio -tanto civil como penal- contribuye a la fabricación de la categoría "usurpador-delincuente", que a su vez justifica un desplazamiento represivo al territorio mismo, incluyendo prácticas policiales.

De este modo, las luchas por tierra y vivienda son intervenidas estatalmente, siendo controladas espacialmente por la represión policial y desplazadas en el tiempo por la judicialización del conflicto. Son las experiencias concretas las que manifiestan que la criminalización es una política de Estado. En este sentido, el juicio oral y público a Diosnel Pérez y Luciano 'Tano' Nardulli por el delito de usurpación y supuesta instigación de la toma del Parque Indoamericano en 2010, en Ciudad de Buenos Aires, iniciado el 16 de octubre de 2015, es un claro ejemplo de esta política de criminalización. Mientras tanto, todos los responsables por las muertes y heridos en la represión estatal durante esa toma han sido absueltos o sobreseídos. Analicemos en profundidad uno de los casos de nuestra región.

\section{El caso de la Toma de Villa Obrera (Fiske Menuco)}

En el barrio Villa Obrera de Fiske Menuco, General Roca (Provincia de Río Negro), como en otros barrios en los que viven familias trabajadoras, la necesidad de acceder a un espacio vital 
para proyectar y desarrollar la vida doméstica, se acentúa y agudiza al encarecerse los precios de los terrenos y de los alquileres.

Debido a la lógica especulativa inmobiliaria, que predomina en la disponibilidad y uso de la tierra urbana desde los años noventa, los hijos de los vecinos de los barrios populares sufren el hacinamiento, al acomodarse en las casas de sus familiares sin contar con un espacio propio para desarrollar sus vidas. Por este motivo, algunos hijos del barrio Villa Obrera realizaron un relevamiento de los hogares y de las personas que venían acumulando necesidades habitacionales, y con dicho diagnóstico elaboraron una propuesta de declaración de utilidad pública que posibilitaría el posterior loteo social de las tierras aledañas a la escuela primaria del barrio.

Ante a la falta de respuestas formales, un grupo de 14 familias comienzan a reunirse para organizarse y decidir cómo seguir con el reclamo. Al mismo tiempo, se enteran de que un empleado municipal y vecino del barrio estaba juntando carpetas y armando otro grupo para acceder a los terrenos en cuestión. Entre la indiferencia formal del ejecutivo local y la operación política de armado paralelo, el conflicto por las tierras se materializa en la toma del jueves 8 de diciembre de 2009, a las 14 horas, por parte de 50 familias aproximadamente.

En principio, lo que se hicieron fueron cuatro infracciones municipales hacia mi persona y tres chicos más que firmamos el acta de infracción (...) vino un inspector municipal -la única persona que vino de parte del municipio- $y$, en base a los datos de la firma, con esos datos nos imputan en la causa de usurpación. (Referente de la toma Villa Obrera, 17/07/12).

A partir de ese momento, se despliega la judicialización del conflicto a través de la criminalización de sus referentes, a quienes no sólo se les procesa legalmente, sino que, además, se los estigmatiza públicamente como "punteros", "delincuentes", "avivados". 


\section{La judicialización}

La causa se inicia en 2009, por parte de Juan Carlos Bagliani, en su calidad de representante de las Sucesiones de "Bagliani Francisco P.T.". Seguidamente se presenta el Municipio de General Roca, formulando denuncia penal contra los ocupantes de la parcela 764, la cual fue cedida a la municipalidad por convenio celebrado con los herederos de Francisco Pedro Bagliani, en el año 1991. Por dicho convenio, los sucesores de Francisco Bagliani ceden al municipio local el inmueble denominado catastralmente como Sección “D”, quinta 077, Parcela “01", en pago de deudas por tasas y servicios retributivos, y contribución de mejoras.

El municipio siempre invocó que los ocupantes deberían hacer el trámite correspondiente ante el Registro de Datos del Banco de Tierras Municipales, al mismo tiempo que se presentaba como querellante en la causa penal y pedía el desalojo. Una vez judicializado el conflicto, se dio intervención a la Dirección de Métodos Alternativos de Resolución de Conflictos del Poder Judicial (DIMARC), donde se llevó a cabo un proceso de negociación entre los denunciantes y los vecinos. Así se llega a un acuerdo parcial entre los ocupantes de la Manzana $\mathrm{N}^{\circ} 760$ y el Sr. Juan Carlos Bagliani. Sin embargo, no ocurre lo mismo con el resto de los terrenos involucrados.

En la figura de la mediación/negociación, instancia que se impone tanto en los procesos civiles como penales, ya sea desde el ámbito judicial como desde el ejecutivo, se observa el rol que Therborn le atribuye a la judicatura. El acceso a la vivienda es impuesto como una cuestión negociable con el propietario privado frente a un "mediador" neutral: el Estado. Pero no es más que una instancia en la que se busca la sumisión de las clases dominadas. Frente a la amenaza de desalojo, la negociación aparece como única salida, deviniendo en extorsión, lo que implica un retroceso en el proceso de lucha por el derecho a la ciudad. 
La causa, iniciada en 2009, llegó a juicio en 2014, producto de la acusación de la propia municipalidad de General Roca -como propietaria de una de las parcelas, que adquirió justamente por el estado de abandono en que se encontraba el terreno- y de un consorcio denominado La Lonja, quien se atribuía otra de las parcelas del barrio.

El 17 de diciembre de 2014 se dictó sentencia en el juicio oral y público llevado a cabo en contra de seis vecinos del Barrio Villa Obrera, acusados de haber cometido el delito de usurpación y hurto de energía. El juez subrogante, Juan Pablo Chirinos, dictó sentencia condenando al referente de la toma, por su condición de tal:

Si hoy existe una condena es porque fue el propio Olivera quien, al asumir el liderazgo de la toma y su reclamo político, generó prueba en su contra. De asumir otra actitud, con la prueba colectada en autos, quizás hubiera sido imposible este resultado. (Sentencia O.O.M s/Usurpación, 2014)

Los argumentos vertidos en el fallo no sólo dan cuenta de su carácter disciplinador hacia quienes luchan por el derecho a la tierra y la vivienda, sino que además da directivas claras a los poderes ejecutivos en cuanto a la intervención en conflictos de tomas de tierras. "Es exigible al municipio un mínimo de diligencia en el cuidado de sus bienes privados, máxime ante reiterados pedidos y amenazas de actuar por vías de hecho" (Ibíd.). El juez reprocha al municipio no haber procedido al desalojo inmediato de la toma: "Si el combate se va a dar en los estrados judiciales, el resultado será siempre tardío" (Ibíd.). La condena consistió en seis meses de ejecución condicional y el cumplimiento de una serie de reglas de conducta por el término de dos años. Asimismo, se ordenó el desalojo del referente de la parcela de tierra que ocupa. La sentencia pone el énfasis en el carácter privado del conflicto, aun cuando uno de los querellantes era la municipalidad de General Roca. 


\section{La capitalización política}

Mientras todo este proceso de judicialización se desenvuelve, se despliegan mecanismos institucionales que permiten operar políticamente para intentar capitalizar los conflictos sociales, es decir, que posibiliten obtener ciertos beneficios políticos a partir de las intervenciones estatales. En esta dirección y en un contexto electoral, la Secretaría Nacional de Acceso al Hábitat fue creada por el Poder Ejecutivo Nacional mediante decreto 1715/14 (publicado en el Boletín Oficial el 1-oct-2014). Dicha Secretaría tiene como antecedente la Comisión Nacional de Tierras y su principal objetivo es:

(...) promover el acceso al hábitat en su aspecto cuantitativo y cualitativo, mediante la implementación de políticas de urbanización de barrios informales, regularización dominial y producción de suelo urbano [y más específicamente], lograr la regularización dominial de las tierras fiscales nacionales, urbanas y rurales mediante su transferencia a los sujetos de derecho afectados por las políticas de la Secretaría. (Decreto No 1715/14).

A días de su creación, el responsable de dicha Secretaría -el arquitecto Rubén Pascolini ${ }^{8}$ - aclaró que los barrios que recibirían la intervención de la misma están localizados, en general, sobre tierras fiscales, aunque en algunos casos se sitúan sobre tierras privadas en las que no hay conflictos ni judicialización. Es decir, la Secretaría fue creada para regularizar la situación de asentamientos ubicados en tierras fiscales, y no en tierras de privados. En la fundamentación del decreto se sostiene:

Quien estuviese a cargo de la Comisión Nacional de Tierras, cuya pertenencia política es públicamente vinculada a la organización política MILES, cuya referencialidad es D’Elía -líder de la FTV, Federación por Tierra y Vivienda-, una de las organizaciones sociales directamente alineadas con el kirchnerismo desde sus comienzos. 
Que el acceso equitativo al suelo, a la vivienda y a los servicios públicos, así como la mejora de las condiciones de vida de las personas, son objetivos fundamentales del Poder Ejecutivo Nacional. (...) Que para el logro de los objetivos mencionados precedentemente, resulta imprescindible el trabajo coordinado con las diferentes áreas gubernamentales y no gubernamentales con incumbencia en la materia, del ámbito nacional, provincial y municipal. (Ibíd.)

De esta manera, mientras desde el ejecutivo nacional se plantea -normativamente- una coordinación con las provincias y los municipios, las situaciones concretas demuestran que cualquier coordinación tendiente a la regularización resulta problemática: por un lado, el municipio de General Roca, con nota firmada por su intendente Martín Soria, que solicita a la Secretaría se abstenga de intervenir en la toma de Villa Obrera; por el otro, el municipio de Cipolletti, que hizo manifiesto su rechazo a cualquier trámite de expropiación o declaración de utilidad pública, por estar las tomas judicializadas y en zonas en las que el propio municipio determina que no son urbanizables.

Entre las funciones de los departamentos regionales de la secretaría, encontramos que una es: “(...) informar sobre cualquier conflicto en relación con la tenencia de la tierra y el hábitat a la Secretaría Nacional de Acceso al Hábitat" (Ibíd.). ¿Será por eso que, en tiempos electorales, el delegado regional José Rodríguez, organizó reuniones informales -en bares y otros espacios privados- con los referentes de cada una de las tomas, por separado, desconociendo la existencia del reclamo colectivo por parte del Foro por Tierra y Vivienda, con los supuestos propietarios de las tierras, para promover negociaciones que desde hace años están obstruidas, principalmente por la judicialización del conflicto y por la especulación de los propietarios? 
Está claro que la Secretaría entiende que la cuestión de la tierra debe resolverse en el marco de la justicia burguesa, y que el problema de la vivienda entonces es un problema entre privados, a los que el Estado asiste como un aparente mediador neutral, sin responsabilidad ni intereses al respecto. Sin embargo, nos preguntamos, ¿será por eso que en pleno juicio a los vecinos de Villa Obrera, el intendente de la municipalidad de General Roca, Martín Soria, envió una nota a la Secretaría advirtiendo que ésta no se atreviera a intervenir en dicho proceso ni en ningún tipo de negociación con el barrio, porque su referente era un "delincuente" al que el poder judicial iba a condenar? ¿Será por eso que la Secretaría no retomó ningún contacto con los vecinos del barrio Villa Obrera? ¿Será por eso que el juez Chirinos condenó al referente por su actitud de liderazgo?

\section{Las estrategias populares}

Frente al proceso de criminalización, los vecinos desplegaron diversas estrategias, que podríamos clasificar como políticas, jurídicas y sociales.

Políticamente, desde el primer momento en el que organizaron las tomas de tierras, el grupo de vecinos apostó a una estrategia de interpelación directa al poder ejecutivo municipal, con acciones concretas, como la de presentar el proyecto de barrio al intendente en un acto de inauguración municipal y tomarse el Consejo Deliberante para que se tratase la problemática. Asimismo, participó de una reunión de labor parlamentaria en la legislatura de la Provincia de Río Negro.

Jurídicamente los vecinos también desplegaron una participación activa, siguiendo el expediente, buscando asesoramiento jurídico y presentando todos los recursos posibles para evitar el avance de la judicialización. Luego de la sentencia en primera instancia, se ha apelado al Supremo Tribunal de Justicia de la provincia y, en caso de ser ratificada, se apelarán a la Corte Suprema de Justicia de la Nación. 
Socialmente el barrio se dio una doble estrategia: "hacia adentro" y "hacia afuera". Hacia adentro, los vecinos no cesaron en los esfuerzos de consolidar el barrio, construyendo viviendas de material y avanzando en la urbanización, que fue favorecida por la cercanía de los servicios y la ubicación en relación al centro de la ciudad. Hacia afuera, fundamentalmente el referente de la toma mantuvo una presencia continua en los medios de comunicación locales, que contrarrestara el proceso de estigmatización iniciado por el intendente de la ciudad.

"Nuestra pelea ha llevado a que gente que no tenía adónde caerse muerta hoy tenga adonde venirse a vivir con sus chicos (...) yo tengo esa tranquilidad, lo otro no me interesa, no entro en el juego de las supuestas avivadas, ya me tiene sin cuidado". (Referente de la toma Villa Obrera, 17/07/12).

\section{Conclusiones}

A partir del análisis de este caso, podemos observar un despliegue de técnicas y procedimientos destinados a gobernar la precariedad, articulando políticas sociales y penales. "El problema, entonces, no es sólo cómo gestionar la pobreza sino, además, cómo convivir con los excluidos con un programa de inclusión precarizada" (Daroqui, 2014, p. 287).

Son las experiencias concretas las que manifiestan que la criminalización es una política de Estado: el despliegue del aparato punitivo se ha convertido en una de las formas de intervención del Estado en los conflictos por tierra y vivienda, reafirmando que son las clases desposeídas el objetivo principal de las instituciones penales (De Giorgi, 2006, p. 60).

Como hemos planteado, para analizar los procesos de criminalización de los conflictos por tierra y vivienda, resulta necesario dejar de lado la representación normativa del sistema de justicia y sus funciones manifiestas y explícitas, y focalizarse en 
las funciones que permanecen en lo oculto, en aquellas que denominamos "latentes".

Esto se manifiesta en las experiencias concretas, en las que la figura penal utilizada para la criminalización de dichos conflictos es principalmente el tipo penal de usurpación (artículo 181 del Código Penal), que prevé como sanción la pena de prisión. Sin embargo, no parece ser ésta la finalidad del proceso penal en estos conflictos. ¿Cuántas personas se encuentran encarceladas por tomar tierras? Sin lugar a dudas, no alcanzarían las cárceles. ¿Cuáles son entonces las funciones latentes de la aplicación del sistema penal en estas experiencias? La respuesta la encontramos quizás en las características de estos procesos de criminalización, tales como la individualización del conflicto y su carácter permanente.

En lo que refiere al carácter individualizante de la pena, se observa que todos los procesos de criminalización se materializan en la "responsabilidad individual" de una persona. Sin embargo, cabe aclarar que el carácter colectivo del conflicto es tenido en cuenta al momento en que la selectividad del sistema penal opera: hay una voluntad política de judicializar estos conflictos colectivos y los operadores del sistema penal responden a dichos fines. El denominado "Protocolo de actuación ante ocupaciones de inmuebles sin autorización" ${ }^{\prime 9}$ consiste en un instructivo para acelerar la investigación penal frente a tomas de tierras. Da instrucciones para acelerar el proceso penal, la identificación de personas y los desalojos, a la vez que prevé medidas disciplinarias para jueces y policías que no cumplan con las medidas dispuestas en el protocolo.

Es decir, hay una selección de conflictos colectivos en la definición de la política criminal a implementar. Sin embargo, cuan-

La RESOLUCIÓN INSTRUCCIÓN GRAL. No 001/13/PG, es un claro ejemplo de cómo la voluntad política de criminalizar marca la línea de actuación de los operadores del sistema judicial. Dicho protocolo fue dictado por Liliana Piccinini (Procuradora General) en febrero de 2013. 
do empieza a operar el sistema penal propiamente dicho, cuando se inicia el proceso judicial, comienza a operar este carácter individualizante del proceso de criminalización, que implica una reducción de la cuestión a la suma de los actos privados de una persona, recayendo la pena o la amenaza de la misma sobre una persona aislada del colectivo ${ }^{10}$.

Son diferentes los criterios que se activan al momento de realizar esta segunda selección: ¿Quién será el sujeto criminalizado? Criterios que van desde la decisión de los propios vecinos respecto a quien transitará dicho proceso, hasta la selección por parte del mismo sistema penal de quien es el sujeto a "disciplinar". Este último criterio se dio en el caso de Villa Obrera, en la que fue condenado sólo el referente del barrio, por su propia condición de tal.

Si hoy existe una condena, es porque fue el propio Olivera quien, al asumir el liderazgo de la toma y su reclamo político, generó prueba en su contra. De asumir otra actitud, con la prueba colectada en autos, quizás hubiera sido imposible este resultado. Respeto y valoro la participación política, el discurso sincero y la lucha por la mejora de un grupo que no dudo es vulnerable, pero entiendo que el Sr. Olivera realizó un cálculo de probabilidades respecto de su posible condena y, a pesar de ello, actuó. (Sentencia O.O.M s/Usurpación, 2014).

Esta individualización, sin lugar a dudas, deviene en el intento de fragmentación del proceso colectivo que da lugar a la toma de tierras. Sobre esta persona recaerán los efectos del castigo, sin dejar de lado que dicho castigo tendrá un efecto "ejemplificador" y "disciplinador" para todo el colectivo sujeto al desalojo y para cualquier persona que se encuentre en situaciones similares. El

\footnotetext{
10 En este sentido, el juez Chirinos sostiene en su sentencia: "No dudo de la importancia simbólica que este proceso tiene, pero a la par de todo ello, esto no deja de ser un proceso donde se enjuicia a 6 personas concretas" (Sentencia O.O.M s/ Usurpación, 2014).
} 
propio juez Juan Pablo Chirinos lo confirma en su fallo en el juicio a vecinos de Villa Obrera. "Si se busca que esta sentencia tenga fines comunicativos hacia terceros, es decir que los disuada de cometer este tipo de delitos en el futuro, la utilización del dispositivo penal tendría fines que pueden ser considerados valiosos socialmente" (Sentencia O.O.M s/Usurpación, 2014).

Como si esto fuese poco, otra de las características de los procesos de criminalización de conflictos por tierra y vivienda es la larga duración de los mismos, con irregularidades por parte de funcionarios judiciales intervinientes y por la amenaza de desalojo latente e indefinida en el tiempo. Incluso esa amenaza se da en la condena misma, como vimos en el caso analizado.

A lo largo de nuestro trabajo hemos identificado las condiciones económicas y políticas en las que se profundiza el problema del acceso a la vivienda en la Argentina y en particular en la región del Alto Valle. Como correlato de la precarización laboral se acentúa la precarización habitacional en la que miles de familias viven, accediendo a la ciudad a través de asentamientos irregulares.

Ante la generalización de los conflictos por tierra y vivienda, el Estado despliega una política de criminalización de los referentes de estas luchas. Para ello se combinan diversos aparatos y funciones estatales, por momentos de manera complementaria, por momentos de manera contradictoria. A partir de un análisis de caso, vimos que es el poder ejecutivo municipal el que en primer lugar enfrenta el conflicto, comenzando con la aplicación del sistema de contravenciones y siguiendo con la denuncia penal. El poder judicial despliega una serie de procedimientos selectivos que individualizan y constriñen a los referentes de los conflictos, avalando la estigmatización social y el control territorial por parte de fuerzas represivas.

Para un gobierno que se autodefine como progresista y defensor de los derechos humanos, esta estrategia tiene un costo político que debe ser atenuado, al menos retórica e institucionalmente. Por eso, y en un contexto de elecciones, se reimpulsa la labor de 
la Comisión Nacional de Tierras, creando la Secretaría de Acceso al Hábitat, desde la que se asume la problemática, se desplazan al pasado sus causas y se despliegan estrategias discursivas y prácticas de manipulación política que, lejos de oponerse y revertir la criminalización de los conflictos, no hacen más que dilatar los tiempos e intentar obtener beneficios políticos.

Luego del análisis realizado, sostenemos que en los conflictos por tomas de tierras el Estado kirchnerista interviene intentando ocultar los mecanismos por los que efectivamente la lógica de mercado se impone a través de su intervención política (Bonnet, 2012). Mediante la criminalización de las tomas de tierras se reinscriben los conflictos en el régimen de primacía de la propiedad privada, se someten a la individualización y al disciplinamiento, para intentar luego travestirse en mediador posible de una negociación asimétrica y violentamente discrecional.

A la negación del derecho a la ocupación le sigue la criminalización de las luchas, la precarización del territorio vital y la naturalización de la apropiación privada y de la mercantilización de la tierra.

Como sostenemos en los barrios: la amenaza del desalojo implica nada más y nada menos que una negociación a punta de pistola. Por lo que resistir a este tipo de políticas no solo implica construir sólidamente organizaciones colectivas que desmantelen las operaciones políticas -que en algunos casos aparentan una oposición entre poderes y niveles del Estado y otras veces muestran sin más su complicidad estructural-, sino fundamentalmente cuestionar el régimen de propiedad privada y la dominación clasista que permanecen naturalizadas.

\section{Referencias}

Astarita, R. (2010). Mitos sobre los tiempos K. Recuperado de http:// rolandoastarita.wordpress.com/2010/08/17/mitos-sobre-los-tiempos-k/ 
Bonnet, A. (2012). La crisis del Estado Neoliberal en la Argentina. En M. Thwaites (ed.). El Estado en América Latina: continuidades y rupturas. Santiago de Chile: Arcis-CLACSO.

Bonnet, A. y Piva, A. (2013). Un análisis de los cambios en la forma de Estado en la posconvertibiidad. En J. Grigera (comp.) Argentina después de la convertibilidad (2002-2011). Buenos Aires: Ed. Imago Mundi.

Daroqui, A. (coord.) (2014). Castigar y gobernar. Hacia una sociología de la cárcel. La gobernabilidad penitenciaria bonaerense. Buenos Aires: CPM y GESPyDH.

De Giorgi, A. (2006). El gobierno de la excedencia. Posfordismo y control de la multitud. Madrid: Ed. Traficante de sueños.

Fals, O. (2012). Ciencia, compromiso y cambio social. Antología. Buenos Aires: El Colectivo.

Giaretto, M. y Naffa, V. (2014). Cuando habitar la tierra es 'delito'. La criminalización de las luchas por la tierra en ciudades del Alto Valle de Río Negro. Ponencia presentada en las VI Jornadas de Historia de la Patagonia, Facultad de Ciencias de la Educación, Universidad Nacional del Comahue, Cipolletti, 12, 13 y 14 de noviembre.

Giaretto, M. y Diez Tetamanti, J.M. (2013). La vivienda como problema. Aproximaciones a las políticas habitacionales en Chile y Argentina. En AA.VV. Debates sobre la desmercantilización de los derechos sociales. Análisis de las políticas estatales de Chile y Argentina en la primera década del siglo XXI. Gral. Roca (Fiske Menuco): Ed. Publifadecs.

Giaretto, M. (2011). Ciudad en conflicto. Un análisis crítico de las relaciones entre Estado capitalista y tomas de tierras urbanas. Fiske Menuco (Gral. Roca): Ed. Publifadecs.

Gramsci, A. (2004). Antología. Selección, traducción y notas de Manuel Sacristán. Buenos Aires: Siglo XXI.

Grigera, J. y Eskenazi, M. (2013). Apuntes sobre la acumulación de capital durante la posconvertibilidad. En J.Grigera (comp.), Argentina después de la convertibilidad (2002-2011). Buenos Aires: Ed. Imago Mundi.

Korol, C. (2009). Criminalización de la pobreza y la protesta social. Buenos Aires: Ed. El Colectivo.

Poulantzas, N. (1983). Estado, poder y socialismo. México: Siglo XXI. 
Putero, L. (2010). Vivienda, déficit habitacional y políticas sectoriales. Recuperado de: http:/ /www.ciges.org.ar/documentos / Vivienda_Deficit_PoliticasSectoriales.pdf

Sautu, R., Boniolo, P., Dalle, P. y Elbert, R. (2005). Manual de Metodología. Buenos Aires: CLACSO.

Salvia, S. (2009). Estado y conflicto interburgués en Argentina. La crisis de la convertibilidad (1999-2001). En A. Bonnet y A. Piva, (ed.). Argentina en pedazos. Luchas sociales y conflictos interburgueses en la crisis de la convertibilidad. Buenos Aires: Peña Lillo.

Therborn, G. (1979). ¿Cómo domina la clase dominante? Aparatos del Estado $y$ poder estatal en el feudalismo, el capitalismo y el socialismo. México: Siglo XXI.

\section{Fuentes primarias}

Entrevistas realizadas a referentes de Toma Villa Obrera, 5/07/12 y $17 / 07 / 12$.

Encuentros con los vecinos/as para trabajar estrategia jurídica desde septiembre a noviembre de 2014, una vez por semana.

\section{Fuentes secundarias}

Sitio oficial de la Comisión Nacional de Tierras para el Hábitat Social. Recuperado de http:/ / www.tierras.gob.ar/index.php

Decreto No 1715 (2014), Decreto No 357/2002. Modificación, Publicado en Boletín oficial de fecha 01-10-2014. Argentina. Recuperado de http://www.infoleg.gob.ar/infolegInternet/anexos/235000-239999/235648/norma.htm

RESOLUCIÓN PROCURADORA GENERAL Nº 001/13/PG. Recuperado de http://www.rionegro.com.ar/diario/funciones/ binario / generico.aspx?idart $=1081274 \&$ tipo $=2 \&$ idcon $=348$ 8984\&P=NOWEBCACHE

Sentencia O.O.M s/Usurpación (2014): Juzgado Correccional $\mathrm{n}^{\circ} 18$ de la II Circunscripción de la Provincia de Río Negro, Argentina, Expte. $\mathrm{N}^{\mathrm{o}} 05022-18$, Sentencia $\mathrm{n}^{\circ} 80$, tomo $\mathrm{n}^{\circ} 1$, folio $\mathrm{n}^{\circ} 182$, de fecha 17/12/2014. Juez ponente Juan Pablo Chirinos. 